\title{
Sociabilidades conflictivas yalienación residencial. Los malestares de la vivienda en alquiler en asentamientos populares consolidados de Lima Sur
}

Sección ESTUDI0S

RECIBIDO: $15 / 10 / 2020$

APROBADO: 30/10/2020

PUBLICADO ONLINE: 18/12/2020
Anderson A. García Cristóbal

Ministerio de Vivienda, Construcción y Saneamiento del Perú

agarciacristobal@gmail.com

https://orcid.org/0000-0001-5891-3310

\section{RESUMEN}

El texto aborda el submercado de alquileres en asentamientos populares consolidados de Lima sur, a partir de los malestares de sus inquilinos; para ello se emplean los conceptos sociológicos de sociabilidad y subjetividad. Mediante el primer concepto, se describe cómo este sistema habitacional está generando relaciones altamente conflictivas. Mediante el segundo concepto se aborda cómo la experiencia del inquilinato se vive como alienación residencial. Se concluye mostrando cómo la experiencia residencial de los inquilinos nos presenta la peor cara de la densificación habitacional y se proponen algunas recomendaciones de política pública.

PALABRAS CLAVE: ciudad informal; vivienda en alquiler; alienación residencial.

\section{Conflicting sociabilities and residential alienation. The discomforts of rental housing in settlements popular consolidated of Lima Sur}

\section{ABSTRACT}

In this article we discuss the submarket of rental housing, based on the discomforts of this tenure regime in consolidated popular settlements in southern Lima; from the concepts of sociability and subjectivity. Through the first concept, we describe how this housing system is generating highly conflictive relationships. The second concept addresses how that tenancy experience is lived as residential alienation. We finish showing how the residential experience of the tenants presents us the worst side of densification. At last, we propose some recommendations for public policy.

KEYWORDS: Informal city; rental housing; residential alienation. 
"Mi casa es membranosa y viva, pero no es asunto uterino. Estoy hablando del lugar de mi cuerpo que he construido, como el pájaro aquel, con baba" José WatAnABe, Mi casa.

\section{Introducción}

L a ciudad popular está mercantilizándose. Los mecanismos actuales de acceso primario al suelo y a la vivienda para los sectores populares, ya no pasan necesariamente por las tomas u ocupaciones que caracterizaron el proceso de formación de las llamadas "barriadas".1 Hoy, asistimos a un doble proceso mediante el cual, los sectores de menores ingresos acceden al suelo y a la vivienda mediante el submercado de loteos y el submercado de alquileres.

Mientras el primero se desarrolla fundamentalmente en la periferia de la ciudad, en suelo nuevo; el segundo tiene como escenario a los asentamientos populares consolidados, en suelo ya urbanizado. En ambos casos, lo que caracteriza a este proceso es que el espacio habitacional es tratado como mercancía, es decir predomina su valor de cambio frente a su valor de uso; un hecho relativamente reciente en la historia de la vivienda. ${ }^{2}$

Sin embargo, aunque la dimensión propiamente mercantilista de la vivienda está cobrando mayor relevancia en el debate internacional; lo cierto es que el espacio habitacional sigue siendo un espacio vivencial, que también es valor de uso para sus moradores; de allí que no se trate de oponer valor de cambio a valor de uso, sino en preguntarse cómo está afectando al valor de uso de la vivienda, el protagonismo que tiene el valor de cambio en el sistema habitacional contemporáneo. La vivienda, aunque mercancía, sigue siendo el espacio primario en donde los residentes buscan ubicación, tenencia y abrigo (Turner, 1976), es decir donde "espacio y función intercambian carne" (Watanabe, 2013).

1 Tomamos la definición de "barriada" elaborada por Julio Calderón (2016), para quien esta"es producto de un modo de acceso al suelo en que predominan los mecanismos no mercantiles o no comerciales. Es decir, la propiedad del suelo se toma o se ocupa, más que se compra o alquila" (p. 137).

2 Debemos destacar dos recientes investigaciones sobre el submercado de loteos en Lima. Por un lado, Jimena Ñiquen ha mostrado cómo las familias fundadoras de Huaycán, y específicamente los dirigentes que han construido un amplio capital social, despliegan estrategias de acumulación de suelo en zonas de expansión, en donde coexisten tanto el interés económico, como las expectativas previsionales. Nekson Pimentel, por su parte, ha puesto de relieve cómo la expansión de un espacio periurbano como Punchauca, en Lima norte, se desarrolla mediante distintas modalidades del tráfico de terrenos, en el marco de una estructura clientelar que va más allá del vínculo patrón/cliente. 
Por esa razón, este texto aborda uno de estos submercados, el de alquileres, a partir de la experiencia residencial de los inquilinos, unos de los actores residenciales poco visibilizados más allá de los conocidos tugurios o conventillos de los centros históricos. Los inquilinos en asentamientos populares consolidados, creemos, representan una de las nuevas caras de la desigualdad urbana en la ciudad de Lima, y de las ciudades de América Latina en general.

En América Latina, el estudio de las viviendas en alquiler, tanto residenciales como comerciales, ha encontrado su campo de investigación en los llamados asentamientos de origen informal consolidados, como el escenario del submercado informal de alquileres; los cuales, a diferencia de los asentamientos de reciente creación (no consolidados), han sido objeto de las políticas de regularización y presentan lógicas de desarrollo urbano condicionadas por sus procesos de densificación (consolidados).

Una revisión del estado del arte sobre las viviendas en alquiler en la región, permite señalar que se han realizado 3 grandes esfuerzos teóricos en América Latina: a) establecer la relación entre el funcionamiento del submercado de alquiler y su impacto en la estructura físico espacial de la ciudad (Abramo, 2012), b) comprender las preferencias de localización de la demanda sobre la base de las decisiones residenciales de los inquilinos (Parias, 2010), y c) comprender cuáles son las lógicas de los propietarios y sus motivaciones para ofertar viviendas en alquiler (Briceño, 2010). En el marco de estos esfuerzos, este texto se inscribe en el segundo de ellos, a fin de ahondar en la experiencia residencial de los inquilinos.

La metodología que la sustenta, se basa tanto en una encuesta aplicada a una muestra representativa ${ }^{3}$ en el marco de una investigación para el Programa para América Latina y el Caribe del Lincoln Institute of Land Policy; como en entrevistas en profundidad realizadas en el marco de la elaboración de la tesis de licenciatura.

Hemos de advertir, finalmente, que este texto está escrito con la intención de dejar la jerga de un urbanismo que, presto de modismos o recetas, ha devenido poco reflexivo; $y$, por el contrario, acercarnos a la ciudad y más específicamente al sistema residencial popular, desde los lentes de la sociología, que a fuerza de percibirse como en permanente crisis no ha dejado de elaborar preguntas novedosas sobre los problemas públicos más acuciantes.

3 Se trata de una encuesta probabilística, bietápica y estratificada, con selección aleatoria de barrios y selección aleatoria de manzanas; aplicada a una muestra de 378 casos. Margen de error de 0.05 . Los barrios seleccionados fueron P.J. Virgen de Lourdes, P.J. Nueva Esperanza, P.J. Cercado, P.J. Mariátegui, J.C III Etapa Sec. Vallecito Bajo (en Villa María del Triunfo); P.J. Villa El Salvador Sector I (en Villa El Salvador); P.J. San Juanito, P.J. Pamplona Alta (en San Juan de Miraflores) y A.H. San Genaro (en Chorrillos). 


\section{El alquiler como sistema habitacional en asentamientos populares consolidados}

El submercado de alquileres en estos asentamientos, es el más dinámico de los submercados de alquileres en la Lima actual. Como se ha señalado en un trabajo previo (García, Moreno y Galindo, 2020), analizando la última información censal y georreferenciada por tipos de barrios, las áreas de origen informal han presentado una tasa de crecimiento intercensal de viviendas alquiladas (2007 - 2017) del 98\%; muy por encima de la tasa de crecimiento de este tipo de viviendas en zonas de origen formal, de solo un $23 \%$. Es decir, mientras que en las zonas de origen formal ha habido un crecimiento de una quinta parte de sus viviendas en alquiler, en las zonas de origen informal las viviendas alquiladas se han casi duplicado.

Además, mientras que al año 2017, 1 de cada 4 viviendas en Lima era alquilada, más de una quinta parte de estas viviendas se localizaban en los asentamientos populares consolidados, barrios de autoconstrucción que, al menos desde la década de los ochenta, vienen pasando por un proceso de densificación habitacional sin la regulación - ni apoyo debido - del Estado (Riofrío y Driant, p. 1987).

Algunas características estructurales de este submercado, nos permiten dar un diagnóstico poco alentador del sistema habitacional que se está configurando. En principio, se trata de un submercado que otorga incentivos perversos, tanto a arrendadores como a inquilinos, para el fraccionamiento de las unidades inmobiliarias y su consecuente hacinamiento.

La encuesta aplicada a la que hemos hecho referencia (García, et al., 2020), nos ha permitido observar cómo la renta mensual promedio que un inquilino paga por un cuarto equivale al precio total de una canasta básica familiar. Esto quiere decir que si un propietario decide poner en alquiler un ambiente de su vivienda, su subsistencia familiar encontraría un alto nivel de apalancamiento en la renta generada por dicho arrendamiento; pero lo más resaltante es que, en términos económicos, sería más rentable para un propietario alquilar cuartos que departamentos, ya que en este submercado el alquiler de un departamento de 3 habitaciones, en promedio es de S/ 522.55; sin embargo, si se alquilaran las 3 habitaciones por separado (con una renta mensual promedio de $\mathrm{S} / 289.74$ ) un arrendador podría recibir $\mathrm{S} / 869.22$, es decir $63 \%$ más por la misma unidad inmobiliaria. Se trata, en el fondo, de un estímulo al fraccionamiento de la vivienda en contextos en donde existe precariedad laboral y bajas expectativas previsionales para las familias de propietarios.

El hacinamiento, por su parte, es una condición de habitabilidad que está presente en el $40 \%$ de todas las unidades inmobiliarias del submercado de alquileres; 
pero, como era de esperarse, con mayor incidencia en los cuartos, donde el 52.3\% de estos presentan esta condición; frente a los departamentos, de los cuales el 31.3\% están hacinados. ${ }^{4}$ (García, et al., 2020).

Respecto a los arrendatarios, por otro lado, se pudo apreciar cómo el costo promedio del viaje mensual al centro laboral del jefe o jefa de familia, sumado a la renta media mensual del alquiler, representa el $28 \%$ del ingreso mensual familiar para inquilinos de cuartos, y el 27\% para inquilinos de departamentos (García, et al., 2020). Se trata de porcentajes de gastos razonables, que permiten a los arrendatarios contar con márgenes de liquidez para destinarlos a otros bienes y servicios, constituyéndose esto en un incentivo importante para que más residentes vean en el alquiler una opción de tenencia viable.

Esto último ha revelado también que el inquilino prefiere localización y sacrifica habitabilidad, razón por la cual los cuartos alquilados representan casi la mitad de las unidades inmobiliarias de este submercado. Al estar localizados en zonas cercanas a rutas de transporte público o cerca a equipamientos de uso cotidiano, el alquiler de cuartos es altamente atractivo; pese a que suponga, en el fondo, una aceptación a vivir en condiciones de hacinamiento y tugurización.

Otro elemento que ayuda a caracterizar este sistema habitacional es la informalidad de las transacciones. Un alto porcentaje de los acuerdos entre arrendador e inquilino se dan solo de forma verbal, en un $36 \%$ de los casos; y, lo que es más notorio, estos inquilinos sin contratos escritos están presentes en todos los hogares al margen de su nivel de ingresos (García, et al., 2020).

Una vez más, estamos en línea con el argumento de que la informalidad no es un problema de "pobreza", pues el nivel de ingresos no determina la formalidad o informalidad de la transacción, sino la mayor o menor incidencia de dicha informalidad: $43 \%$ de acuerdos sin contrato escrito en hogares con menos de 1 salario mínimo, 30\% de acuerdos sin contrato escrito en hogares con más de 3 salarios mínimos (García, et al., 2020).

De la misma manera, la informalidad de este submercado estaría relacionada con su casi nula regulación pública, como queda demostrado en el alto porcentaje de cuartos sin baño propio, la laxitud de los acuerdos y la poca utilización de contratos ante notarios públicos. La informalidad de este submercado, no solo pone a los inquilinos en bajas condiciones de habitabilidad, sino que les resta capacidad de negociación ante los arrendadores, un hecho que no debe pasar desapercibido ya

4 Entendemos por hacinamiento cuando residen más de 2.5 personas por dormitorio. 
que "los mercados inmobiliarios son políticos de arriba abajo" (Madden y Marcuse, 2018 , p. 68) y siempre confrontan relaciones de poder entre sus miembros.

Finalmente, como hemos esbozado en otro trabajo (García, 2019), el inquilino es un actor que configura una demanda de vivienda específica, ya que sus "preferencias locacionales"5 los dirigen al alquiler en asentamientos populares consolidados, pues estos barrios le permiten gozar de una mejor localización y disponibilidad de servicios públicos básicos. Beneficios que no encontrará en la ocupación ilegal de suelo nuevo no habilitado, al suponerle mayores costos de oportunidad y una mayor exposición al riesgo de la economía delictiva ligada al tráfico de terrenos.

Esta decisión es altamente razonable. Son individuos que han nacido y crecido en barrios que ya cuentan con infraestructura urbana y equipamientos, ¿para qué irían a los bordes de la ciudad popular a buscar un suelo nuevo y pasar por el "calvario" de su habilitación?

En efecto, cerca del $60 \%$ de los inquilinos de la encuesta en mención, ya vivían en este régimen de tenencia hace 5 años, lo que indicaría que se ha trastocado la trayectoria residencial por la cual el alquiler era una etapa momentánea, mientras se encontraba terreno para ocupar ilegalmente o comprar a fraccionadores informales (García, 2019).

Asimismo, un alto porcentaje de los inquilinos, $83 \%$ de los encuestados, no consideró invadir un terreno en los últimos cinco años, y un porcentaje similar tampoco consideró comprar un lote sin título de propiedad. Junto con lo considerado en el párrafo precedente, podemos afirmar que el alquiler de viviendas se convierte en un régimen de tenencia estable en el tiempo, lo que no quiere decir que se trate de una opción deseable para los inquilinos.

Antes que eso, este contexto nos ha permitido reflexionar acerca de los inquilinos como una "demanda atrapada" (García, 2019) entre un submercado de loteos cada vez más hostil (tráfico de terrenos, extorsiones, estafas) y una política de vivienda social que, por sus limitaciones de diseño, no los califica como una demanda efectiva. Si es así, el sistema habitacional que estamos describiendo convierte a los inquilinos en la expresión de la (ya no tan nueva) desigualdad urbana en el siglo XXI.

Este texto explorará, a manera de indagación ${ }^{6}$, la experiencia residencial de los inquilinos desde los conceptos sociológicos de sociabilidad y subjetividad, a fin de darle rostro humano a esta "demanda atrapada".

5 Este concepto se lo debemos a Adriana Parias (2010), quien para el caso de Bogotá ha señalado que los arrendatarios toman sus "decisiones residenciales" sobre la base de una "racionalidad estratégica", por la cual aunque las familias arrendadoras valoran la propiedad, también valoran algunas externalidades, entre ellas "las relaciones socioeconómicas localizadas".

6 Como ha indicado Sennett (2003), la palabra "indagación" sugiere una "investigación imparcial". 


\section{Sociabilidades conflictivas}

Vivir en alquiler es sobre todo "convivir". Fuera de la casa unifamiliar que no es significativa en el submercado de alquileres en asentamientos consolidados, el inquilinato se hace presente fundamentalmente en departamentos y cuartos; en donde la presencia de otros hogares, obliga a compartir espacios comunes.

La convivencia en las urbes ha supuesto, desde el inicio de la llamada modernidad, dos grandes desafíos para quienes viven en ciudades, a los cuales la sociología ha llamado: sociabilidad y subjetividad (Sennett, 2005). En términos sencillos, mientras que la sociabilidad refiere a que la ciudad nos impele a aprender a vivir con extraños, con personas distintas a nosotros; con la subjetividad la urbe nos propone aprender a vivir con nosotros mismos, y a crecer internamente. Ambas funcionan al mismo tiempo.

Aunque para Sennett, estos desafíos - virtudes urbanas, dirá el autor - se han venido agotando en la ciudad contemporánea, sea por la dialéctica entre rigidez y extrañamiento, al inicio del siglo XX; o por la dialéctica entre flexibilidad e indiferencia, en el marco del capitalismo contemporáneo; para nosotros estos conceptos nos ayudan a comprender que los malestares de la experiencia residencial de los inquilinos, comportan tanto una lectura externa (a escala de las relaciones sociales) como interna (a escala de la subjetividad de los individuos). El primer de estos malestares, desde la lectura externa de la sociabilidad, se traduce en lo que denominamos "sociabilidades conflictivas".

Estas se desarrollan en un gradiente de menor a mayor intensidad, dependiendo de si se comparte menos o más espacios comunes. En el primer polo de este gradiente, cuando se comparte un menor número de estos, por ejemplo cuando se alquila un departamento entero, los problemas no son tan intensos y pueden verse reducidos a la generación de bulla que puede afectar a los vecinos del edificio, por ejemplo al organizar actividades o fiestas.

En este polo del gradiente, los conflictos en torno a la sociabilidad toman la cara de una fiscalización constante del cumplimiento o incumplimiento de algunas normas escritas o tácitas de convivencia; como cuando alguna persona visita al inquilino, y la presencia de este "extraño" genera suspicacias.

- En los tiempos que ha estado en las casas alquiladas ¿Cómo se ha llevado con sus vecinos?

- Mayormente he tratado de llevarme bien. Pero hay vecinos que también te molestan. A veces son chismosos, siempre están fijándose si sales o si no sales, qué traes o qué no traes, así andan. (E7) 
En el marco de esta fiscalización, los problemas de convivencia suelen tener mayor intensidad cuando los departamentos o los cuartos alquilados no cuentan con un medidor de la electricidad o del agua potable; razón por la cual los inquilinos buscan vigilar a sus otros vecinos a fin de asegurarse que se realice un uso "racional" de los servicios. Esto ocurre comúnmente en los alquileres en donde se acuerda que el recibo del servicio se pagará en partes iguales, dividiendo el costo mensual entre el número total de residentes, sean solo inquilinos; o entre inquilinos y propietario cuando este último reside en el predio, una situación que es común encontrar en los asentamientos estudiados; por la gran presencia de "arrendadores domésticos"

- Ah, a veces sí. Cuando yo he lavado mucho, están que te miran. Por ejemplo acá el señor no te deja lavar todos los días, una sola vez a la semana no más puedes, porque de ahí el señor te habla. Solamente acá el medidor que tiene es la luz nada más, pero el agua se divide entre todos. Y por eso el señor dice que tratemos de lavar una sola vez, porque luego ustedes no quieren pagar. (E7)

Al otro lado del gradiente, se ubican los problemas de convivencia generados por las propias condiciones habitacionales de la vivienda, cuando se comparten lavaderos, baños, tendederos, es decir mayores espacios de encuentro. Aquí la probabilidad de los conflictos entre inquilinos es muy alta, sobre todo cuando se constata el no cumplimiento de algunas reglas de convivencia no escritas. Un ejemplo de estas reglas no escritas se puede apreciar en el uso del tendedero y en la necesidad de desocuparlo tan pronto como esté seca la ropa que los inquilinos lavan. Esta es una regla no escrita de necesario cumplimiento, a fin de no perjudicar a otra persona. Cuando no se cumplen dichas normas de convivencia, los malestares se hacen evidentes.

- ¿O sea lava a mano?

- Sí, lavo a mano. A veces sí llevo la ropa a la lavandería cuando lo tengo que secar. Pero mayormente tiene su lavadora ella, lo necesario nomás lo que lava, las medias, eso nomás es lo que lava. Pero siempre hay dificultades ahí porque hay que... es un poco complicado.

- ¿Y hay gente que no seca bien...?

- No seca bien la ropa, o a veces no recoge rápido la ropa y no hay espacio dónde tender. Es que es un fastidio vivir en casa alquilada, es un fastidio. No es como

7 Tomamos este concepto de Roberto Briceño (2010), con el cual designa la lógica de la utilización de la vivienda, por parte de sus propietarios, a fin de procurarse un ingreso extra; pero permaneciendo en la misma vivienda. 
tener tú mismo tu propia casa. Y a parte también cuando yo estaba viviendo en el departamento allá en la señora Suly, cuando tendía la ropa arriba en el techo se me perdía la ropa, por eso me salí de allí. (E7)

De todos los espacios comunes, los problemas generados en torno a los baños compartidos se revelan como los más acuciantes ya que, de acuerdo a la información disponible, la mayoría de los cuartos alquilados no disponen de baños propios, y una gran cantidad de los llamados "mini departamentos" que se ofertan en este submercado, carecen de los mismos.

Sobre todo en los predios más hacinados, en donde un mayor número de personas utilizan un solo baño, este ambiente se convierte en objeto de disputa, ya sea porque los inquilinos deben despertar temprano para tener prioridad en su uso, 0 porque al ser usado de forma intensiva por todos los hogares de arrendatarios en el predio, su limpieza exige mayores cuidados que no todos los inquilinos cumplen. Estas dificultades respecto al baño nos lo expone una inquilina al recordarnos por qué prefiere cuartos con baño propio.

- No, yo lo primero que veo es el espacio. Sobretodo que tenga un baño privado. Y cuando he preguntado le dije a la chica si no tenía un cuarto con baño personal.

- ¿Por un tema de seguridad?

- No, más por un tema de higiene, mayormente hay algunos que no limpian, es lo que me han comentado, cuando andan compartiendo baño, es un fastidio estar allí limpiando. (E1)

Como se ha podido advertir, el alquiler de cuartos es el que más problemas de convivencia acarrea, tanto por los pagos comunes de servicios de agua y luz, como por su dependencia respecto a las áreas de servicios comunes, y porque los inquilinos de cuartos son los actores más vigilados por los propietarios. Asimismo, es importante ver cómo estos problemas se dan tanto entre pares (inquilino a inquilino), como en relaciones de subordinación (propietario a inquilino).

La relación entre sociabilidad y vivir en alquiler en barrios consolidados se torna aguda, en la medida en que este régimen de tenencia solo se explica porque los barrios consolidados entran a una nueva etapa de su desarrollo: la densificación habitacional. Este concepto ha sido interpretado para la ciudad popular como "el proceso en el que se agregan nuevas unidades de vivienda en los aires o al costado de una vivienda ya producida o en producción" (Zolezzi, Tokeshi y Noriega, 2005, p.11). 
Aunque se trata de un concepto urbanístico, en términos sociológicos la densificación habitacional exige de los residentes, mayores habilidades para convivir con personas que no son iguales a uno. Un dato importante para resaltar la pertinencia de la sociabilidad en este submercado, es que contrariamente a lo que se piensa, la mayoría de los inquilinos han sido desconocidos por los propietarios antes de iniciada la transacción; y por lo tanto deben desplegar estrategias de convivencia.

Un primer tipo de estrategias es el "dejar de hacer", es decir, cuando los inquilinos deben renunciar al desarrollo de sus actividades personales en la vivienda; a cambio de reducir la presión de vigilancia de sus co-residentes.

- $\quad$... O sea que usted, ¿dónde festeja sus fechas importantes?

- Me voy a una fiesta, así.

- No lo hace en la misma casa.

- No, y si vienen a la casa, debo estar diciendo: "No hagan bulla". "No griten".

- ¿Así?

- Las inquilinas del costado se molestan, se quejan. (E9)

Otro tipo de estrategias de resolución se da cuando el costo compartido del servicio de electricidad no resulta razonable respecto a lo que cada inquilino considera "justo". En estos casos, hemos constatado que los inquilinos instalan medidores internos, a fin de contar con una lectura objetiva del servicio. En la gran mayoría de los casos, su instalación es un costo que los inquilinos deben efectuar por cuenta propia, aunque siempre con la autorización previa de los propietarios.

- Para sacar el medidor la dueña firma algo?

- No, nosotros lo hacemos así nomás, si lo pago afuera me cobran 750 soles. Es un medidor interno, no es medidor de Luz del sur. Yo lo divido y lo multiplico de ahí y la vecina también tiene uno igual y vemos si coincide con el general. (E3)

Lo que se debe rescatar de esta experiencia es que la sociabilidad conflictiva es el resultado de un sistema habitacional cuyo equilibrio es garantizado por la regulación social, entre los actores; antes que por la intermediación de las instituciones públicas, es decir la regulación política. La regulación social demanda mucha participación de los actores en el sistema habitacional, a fin de mantener en buenos términos las relaciones interpersonales, lo que la vuelve desgastante; $y$, lo que es más característico, demanda gastos económicos a los inquilinos a fin de traducir conflictos, en acuerdos. 
- ¿YY cómo hace con el pago de los servicios, agua, luz?

- Ah ya, para el pago del servicio tienes tu medidor.

- ¿Acá cada quien tiene su medidor de agua y luz?

- Ajá. Cada uno.

- ¿Y quién es el que revisa eso?

- El dueño.

- ¿El dueño es el que revisa y él hace el descuento?

- Claro, a él le llega ese recibo, y de ese recibo nomás el saca la cuenta

- ¿Y en anteriores casas le ha pasado que no había medidor?

- No, no había.

- ¿Y cómo hacían ahí?

- Nos dividíamos nomás. Pero, pensábamos que estábamos pagando mucho.

- Ah ¿Se dividían en partes iguales así alguien gaste poco?

- Poco o más, igual nos dividíamos. Pero no está bien, no es así pues, uno tiene que ver con su medidor. Depende lo que tú gastes pues. (E7).

Como se habrá podido advertir en los testimonios previos, la sociabilidad conflictiva del inquilinato en estos asentamientos tiene sus bases en lo que Remy y Voyé (2005) Ilamaron "control ecológico"; es decir, "un control basado en la visibilidad y la observación directa y en la capacidad de todos de conocer las actividades de cada uno multiplicando los comentarios personalizados" (p. 34). Como indican estos autores, mientras que en contextos no urbanizados este control expresó la solidaridad incondicional y la confianza recíprocas; en la actualidad se interpreta de manera negativa, como la expresión de una vigilancia y enjuiciamiento permanentes.

La expresión de esta vigilancia es mayor en los casos donde el propietario es co-residente. Aquí, la solución a estos conflictos no pasa tanto por encontrar un punto de equilibrio entre inquilinos, sino que "la solución" es la expresión de la autoridad del propietario.

En estas situaciones, el propietario es el vigilante tanto de los acuerdos de convivencia como del uso "razonable" de los servicios. En la medida que el propietario es un co-residente del predio, cualquier problema en torno a la convivencia afecta a su propia experiencia residencial.

La relevancia teórica del concepto de sociabilidad, supone un desafío para el estudio de los sectores populares en la ciudad, que por décadas privilegió un acercamiento desde el concepto de "comunidad", antes que de sociabilidad. Mientras que el concepto de "comunidad" designa un grupo unificado por relaciones de solidaridad basadas en la asunción de un "nosotros" compartido; la sociabilidad solo es posible cuando tratamos con "otros". 
El protagonismo teórico de la comunidad, explicaría por qué los problemáticos aspectos de la convivencia no fueron visibilizados por una sociología urbana presta a poner en primer plano a un "colectivo" más o menos unificado, algunas veces llamado "movimiento de pobladores", otras"organización barrial"; o más aún, que cuando abordara el problema de la vivienda, lo hiciera privilegiando la de tipo unifamiliar, antes que la multifamiliar.

Solo un proceso de densificación habitacional puesto en evidencia, podría llamar la atención acerca de la necesidad de estudiar cómo se convive en las viviendas multifamiliares en la ciudad popular, viviendas en donde ya no solo viven juntas familias de distintas generaciones, una suerte de "residir entre nosotros"; sino hogares sin vínculo familiar, "residir con otros".

\section{Alienación residencial}

El segundo de estos grandes malestares, esta vez desde una lectura interna, se traduce en lo que denominamos "alienación residencial". Para explicarlo, debemos relacionarlo al concepto de "subjetividad", definido por la sociología como la producción del sentido que, acerca de sí mismos, realizan los individuos en interacción con los demás y en el marco de ciertos espacios sociales.

Simmel fue quizá el primero en desarrollar este concepto y vincularlo con el espacio social más importante de la modernidad: las metrópolis. Para este autor, las grandes ciudades generan un tipo de individualidad por la "intensificación del estímulo nervioso"; de allí que el urbanita moderno intente "preservar la vida subjetiva ante el poder avasallador de la vida urbana" $(2005$, p.2), esta preservación hace que "la indiferencia" $y$ "la reserva" sean las características de la vida social cotidiana en una gran ciudad.

Dicho en breve, el espacio social da forma al sentido que tiene de sí un habitante. Pero esto no es algo que solo ocurra a escala de una gran ciudad. Hoy esta interrogante viene tomando forma a escalas más íntimas de habitabilidad, como en el caso de la vivienda. En ese sentido, ¿puede la experiencia residencial, impactar en la producción de sentido, en la subjetividad, de sus moradores?

Diversas investigaciones y estudios han dado una respuesta afirmativa a esta pregunta. De hecho, la defensa que hiciera John Turner sobre la autoconstrucción, en los años 70, tiene como telón de fondo el concepto de subjetividad, al señalar que "la libertad de construir" sería el único sistema de provisión residencial capaz de generar un alto impacto en la realización personal. De allí que propusiera que los "pobladores" deban estar involucrados en todas las decisiones del proceso 
constructivo de sus viviendas (desde el diseño hasta el financiamiento). La vivienda para él, era un verbo (Turner, 1976).

Si la vivienda tiene un impacto en la realización personal, es porque es objeto de "apropiación", en el sentido teórico que Michel de Certeau le otorgaba a todo objeto de consumo. Para este autor, los usuarios constantemente le dan un sentido, un significado, a los objetos que frecuentemente utilizan (1984). Si esto es así, como creemos, lo contrario también es posible, es decir el uso de un objeto también puede tener para su usuario un sentido de desposesión, es decir alienación.

Giddens y Sutton (2014), definen como alienación a la"separación o alejamiento de los seres humanos del algún aspecto esencial de su naturaleza o de la sociedad, que a menudo da lugar a sentimientos de impotencia y desamparo" (p. 79). Aunque se cuenta con bastantes referencias de la aplicación de este concepto al análisis de las condiciones de trabajo y el capitalismo industrial; el concepto también viene siendo utilizado en los campos de la criminología, los estudios de la salud y demás investigaciones con enfoques psicosociológicos.

Recuperar el concepto de alienación en el marco de los estudios de la vivienda, nos permite poner el foco en la dimensión subjetiva de la experiencia residencial, así como mostrar que los sistemas habitacionales recrean relaciones de poder entre los actores con un impacto en el carácter personal y el respeto propio (Sennett, 2003).

En el campo de los estudios de la vivienda, Madden y Marcuse han desarrollado este concepto, a fin de cuestionar "la experiencia psicocial que se manifiesta como precariedad, inseguridad y desempoderamiento; engendrado por el actual sistema habitacional de las viviendas hipermercantilizadas" (2018, p. 77).

Para estos autores, la tragedia de la alienación residencial es que las familias no pueden moldear su entorno doméstico como desean, ya que su vivienda es el instrumento del beneficio de otros.

Este concepto no es aplicable exclusivamente al régimen de alquiler. De hecho, la propiedad de una vivienda en contextos hipermercantilizados, su alto costo, sumado a las altas condiciones del crédito del actual sistema financiero; genera en los propietarios modernos una creciente inestabilidad anímica. Así, la alineación residencial se manifiesta en la propiedad de la vivienda, cuando esta se ejerce en medio de los vaivenes de la débil estabilidad laboral y las dificultades para mantener un nivel de ingresos, sostenible en el tiempo.

Desde la experiencia de nuestros entrevistados, la primera forma en que se manifiesta la alineación residencial es lo que llamamos la laxitud de los acuerdos. Para entender esto, debemos saber que este submercado se regula fundamentalmente por contratos escritos entre las partes, sin la intermediación de un notario; 
pero también, y con una presencia notable, por contratos verbales sin que medie un acuerdo escrito.

- Porque lo veo que es mucho. Muy caro. Y a veces también le digo al señor de repente, quizás, unos dos meses más y me voy a uno más chico.

- ¿Ah sí? ¿Pero usted no tiene un contrato que diga que se alquila por tal tiempo?

- No, no, no. No te hacen con contrato acá.

- ¿Es así verbal nada más?

- Sí. Si quiere ya se puede retirar. Si usted puede pagar o no puede pagar ya normal. (E15)

En ambos casos, estos acuerdos (escritos o verbales) no impiden, y esto es lo importante, que se realicen "ajustes" sobre la marcha. Un ejemplo de estos ajustes se da cuando los inquilinos incorporan a nuevos residentes, por lo general familiares, a quienes alojan en la vivienda alquilada; y el propietario pide un "ajuste" del precio.

Aunque es posible que esta acción del propietario se realice con la finalidad de penalizar un posible subarriendo, lo cierto es que es una muestra de que los inquilinos no pueden disponer de su espacio habitacional como ellos quisieran.

- ¿Conoce a otras personas que vivan alquilando?

- Si, sus hermanas de mi paisana, ellas alquilan, han alquilado un departamento de 700 soles, pero tiene hartos cuartos y pagan entre todos. Y ahora ha venido otra hermana con sus hijitos y les han aumentado 200 más, en total 900 soles. ¡Hala, no. Mucho! Varias son las que alquilan, mis amigas del colegio, del inicial, todas casi la mayoría alquilan. No sólo yo. (E3)

Estos "ajustes" sobre la marcha también se dan cuando los propietarios descubren que los inquilinos hacen un uso "excesivo" de algunos electrodomésticos y les suben el precio que cobran por los servicios, o la renta mensual (cuando el acuerdo inicial incorpora "luz y agua" en dicho monto).

La laxitud de los acuerdos, es cierto, tiene un componente de flexibilidad que beneficia a los inquilinos, como cuando pueden negociar algunos días de tolerancia para el pago de la renta mensual. Sin embargo, los propietarios también pueden requerir que la renta mensual sea pagada antes de la fecha pactada, es decir cuando surge algún imprevisto y se requiere liquidez inmediata.

- Yo trato de ser puntual siempre, pero siempre no falta que me paso como 5 días, tengo que pagar el 16 y pago el 18, siempre. No, no importa me dicen. Pero cuando él me dice, no, tienes que pagar antes, necesito un 14, o sea antes que se cumpla la fecha, allí si tengo que hacerlo. (E12) 
Esta flexibilidad, es una muestra de la laxitud que otorga la regulación social al interior de este submercado; y de la poca o nula presencia de la regulación política, expresada en el marco jurídico que, en materia de arrendamiento, está vigente en la legislación.

En casos más extremos, la laxitud de los acuerdos puede acarrear que dichos "ajustes" se traduzcan en desalojos, sobre todo cuando los propietarios son coresidentes y no pueden "tolerar" las formas de convivencia de sus inquilinos, 0 imponen cobros adicionales sobre la base de evidencias poco claras, como los aumentos del recibo de los servicios de electricidad o agua, cuando no existe un medidor independiente que garantice una evaluación justa del consumo.

- Ha pensado mudarse a otro distrito?

- Si hubiera oportunidad sí. Pero no hay seguridad, a veces se alocan y a las 2 semanas te botan. He escuchado así, que si los inquilinos hacen mucha bulla los botan. Una amiga que estaba viviendo, ella se fue por que la señora mucho le cobraba de agua y luz. Pero no solo el señor era problemático, sino también los demás inquilinos que hacen mucha bulla. (E3).

Aparte de la laxitud de los acuerdos, otra muestra de alienación residencial está relacionada a las condiciones de habitabilidad de la vivienda alquilada, en las que se recrean verdaderas condiciones de tugurización. Aquí, fundamentalmente son los inquilinos de cuartos los que sufren esta experiencia que se traduce en falta de privacidad, por un lado, como en la adaptación forzada a dichas condiciones, por el otro.

- ¿Y ese cuarto no es que tenía salida independiente de la casa?

- No, tenía que pasar por la puerta principal de la dueña.

- ¿Y cómo hacía para cocinar?

- Ahí me las tenía que ingeniar.

- ¿En el mismo cuarto?

- Claro, o sea tenía que abrir las ventanas lógicamente. Tenía que yo ingeniármelas. (E4)

Estos relatos nos permiten afirmar que son el "control ecológico" del propietario y las arbitrariedades de este, las muestras más directas de la alienación residencial en este submercado. Llevados hacia un extremo, las arbitrariedades pueden tornar a la experiencia residencial como insufrible. 
- Más que eso, una vez, hace unos 7 años que yo alquilaba un espacio por acá por Villa El Salvador, y de la nada el señor me quería... cada mes me subía 50 soles innecesariamente. Él decía:"no, que ha subido el agua". Yo le respondía: " $¿ Y$, el recibo?"Ya, luego te lo doy", me respondía. Y yo a veces por apurado le decía "ya, tome", y cada mes me iba subiendo más y más y más. Y era como que "oye ¿y cuánto me estás cobrando?". "No, sabes qué, voy a cobrar más el alquiler. "Oye, pero eso se avisa con un mes, dos meses, de anticipación, por lo menos, para buscar otro espacio"."Sí, pero surgió de último momento"."No, esas cosas no surgen de último momento". Y yo ya le dije "sabes qué, hasta acá" le dije yo. Y me dijo "no, sabes qué, lo he pensado bien, así que mantengamos el precio, como debía ser".Y yo le dije "no, no, y no". Ya cuando comienzan con eso, cuando una persona ya jala muy extraño, ya prefiero, "sabes qué, chévere tu opción, busca alguien que te pague, respeto tu idea pero yo no, no me la vas a hacer a mí" le digo. (E6)

Dejémoslo claro, las arbitrariedades que estamos describiendo no pueden ser interpretadas como meras acciones individuales. Dichas acciones se despliegan al interior de un sistema residencial que describe un equilibrio -0 mejor dicho desequilibrio- de poderes entre arrendador e inquilino.

Nuevamente aquí, no queremos decir que estas acciones sean generalizables a todo el sistema residencial que describimos. Sin embargo, ante la evidencia de que los acuerdos de regulación social son laxos, las arbitrariedades de los arrendadores son la expresión de que los inquilinos son sujetos vulnerables y, con ello, la nueva cara de la desigualdad urbana en la ciudad popular.

- ¿En todo ese tiempo cómo se ha llevado con los propietarios? ¿Alguna vez le ha tocado un propietario que sea molestoso, injusto, de repente?

- Una vez sí me tocó así. ¡Uy! que el señor antes que pase el mes ya tocaba la puerta, que tenía que pagar, así. No dejaba estar tranquilo. Después en las noches, por ejemplo, no quería que venga mucha visita, en la noche no quería que hagamos bulla, o sea no podíamos hacer un cumpleaños así normal. Te prohibían.

- ¿Ah no?

- Te prohíben.

- ¿Y eso está escrito en un contrato o siempre es de boca?

- No. No está escrito. Es de boca nada más, no está escrito en un contrato. (E7)

De la misma forma que las arbitrariedades. El "control ecológico" de los propietarios, llevado al extremo, genera que los inquilinos no puedan desplegar su sentido de "apropiación" sobre la vivienda: 
- Entonces a eso vamos, no hay confianza y aparte dicen que "Mira que el agua. Así han ensuciado allí, arréglenlo ustedes..."Tantas personas que vienen no sabemos quién es. Y uno ve eso. La comodidad. A veces te dan un mes para que tú puedas buscar otro lugar. Eso todo viene en el contrato. Te dan como un mes de garantía. Y ven: "esta pared no estaba así...o el techo no estaba así, tienes que tener cuidado... ten o lo dejas como está; entonces no te doy tu garantía". (E8)

Al mismo tiempo que el inquilino no puede desplegar un sentido de apropiación adecuado sobre la vivienda, también experimenta una desvaloración. En la medida que el estatus del inquilino se construye alrededor de la figura del propietario, se constituye como "el otro del propietario", con grandes rasgos de negatividad.

Expliquemos mejor esto. Siguiendo a Martucelli (2015) en su caracterización de las consecuencias del "proyecto reglamentador" de la década de los 90 , se debe tener en cuenta que "la casa propia ${ }^{8}$ es la expresión extrema del individualismo metonímico (...) no es pues una cuestión de tener sino de ser. Esa es la significación política de la posesión de algunas piedras en el desierto (p. 288).

Al constituirse como "el otro del propietario", el inquilino es un actor que no goza de prestigio en el sistema habitacional actual, tan consagrado a la vivienda en propiedad. Esta descalificación proviene tanto de los familiares o allegados, propietarios, como de la sociedad en general:

- Alguna vez alguien de su familia le ha criticado por seguir alquilando?

- Si, mis tíos me han dicho"ya debes buscarte un terreno"o"entra aquí, averigua en los panamericanos porque de ahí lo van a vender". No, a mí no me gusta vivir en departamentos. Porque esa tierra es movida, allí ha habido desagües, y un departamento es para pocas personas. Aunque sea una casita así chocita, así quiero vivir. (E3)

Pero no solo es descalificado por los demás, también por sí mismo. Algo que solo es posible entender, nuevamente, si se presta atención a la importancia que tiene la casa propia en la configuración del individualismo limeño, y por ende de una trayectoria residencial que, se cree, debe terminar en la casa en propiedad como símbolo de la realización individual.

Si los inquilinos se autodescalifican, es porque se perciben como actores poco eficientes en dicha trayectoria residencial. Ya sea porque su condición de inquilinos no les permite generar ahorros que desencadenen en la compra de un lote, una

$8 \quad$ El subrayado es nuestro. 
vivienda unifamiliar, o un departamento; o porque no quieren asumir el "costo de la invasión"; el inquilino se percibe fracasando ante una ideología residencial que encuentra en la vivienda en propiedad, la única forma de tenencia capaz de otorgar seguridad ontológica.

- lo que ahora le están proponiendo a mi hijo es comprarse una casa, porque dice que viviendo en alquiler no se va a poder. Nosotros ya tenemos 20 años, mira cuánto hemos gastado para vivir, hace rato ya hubiésemos comprado nuestra casa. (E4).

Aún más, esta descalificación los lleva considerar que el dinero invertido en el alquiler es un dinero desperdiciado.

- ¿Ha pensado en otras opciones posibles como por ejemplo comprar una vivienda...?

- Uy, yo eso quisiera. Pero cómo no hubiera una facilidad digo yo, porque yo acá estoy pagando casi como 600 soles al mes. jAl mes!. Y a los dos meses cuánto estoy pagando, 1200 . ¡Al año cuánto me sale!

- Casi más de 6000 soles.

- Es como si yo estuviera regalando mi plata. (E7)

Pero es quizá la inseguridad de la vivienda, la forma más cruda de esta alienación. Para aclarar a qué tipo de inseguridad hace referencia la alineación residencial, Madden y Marcuse recurren al concepto de "seguridad ontológica", que recuperan del psiquiatra escocés R.D. Laing, el mismo que puede definirse como"la sensación de que la estabilidad del mundo es algo que se puede dar por supuesto" $(2018$, p. 88).

Cuando no existe seguridad ontológica, la posición de poder de los propietarios hace que estos tengan "la última palabra"; una realidad que no siempre es usada en pro de la mejor convivencia sino en beneficio personal.

- Para mí no es justo porque cuando yo entre la señora me dijo un precio que es doscientos cincuenta, y me ha visto, así, un día, haciendo hervir mi agua en una hervidora.

- Ya...

- Y me dijo que por eso te voy a cobrar más. Desde ahí me empezó a joder. Tanto que "si no tienes para pagar ese monto, te tienes que retirar; paga lo que me debes y te vas. Si no quieres pagar más." Entonces como yo le entiendo, le digo a mi esposo que vamos a quedarnos acá, hay que pagar entonces, caballero, lo que ella está pidiendo. (E10). 
Aunque se trata de un estado subjetivo, la seguridad ontológica depende de las condiciones estructurales de la que forma parte. Un ejemplo contemporáneo es cuando un determinado sistema habitacional, privilegia al extremo el valor de cambio de las viviendas, frente a su valor de uso. Los residentes en estos sistemas habitaciones, hipermercantilizados, no encuentran seguridad en su vivienda, porque saben que en cualquier momento serán desalojados; y por lo tanto no tienen la libertad de "crear un hogar como un espacio de estabilidad psicológica y económica" (Madden y Marcuse, 2018, p. 93).

Subrayemos finalmente esta idea, mediante la seguridad ontológica garantizamos un acceso estable al espacio habitacional, pero más aún garantizamos el control sobre dicho espacio en tanto que residentes. De allí que no sentirse seguro, ni dar por hecho el sentido de "apropiación "de una vivienda, sea lo contrario a la seguridad ontológica, es decir, sea alienación residencial.

\section{Conclusiones: Carta de ciudadanía al alquiler popular}

Sociabilidad conflictiva y alienación residencial. He aquí dos problemas que, preliminarmente, constituyen los malestares de la vivienda en alquiler en asentamientos populares consolidados. Lo que se pudo advertir como una oportunidad, es decir el aprovechamiento de la densificación habitacional para generar oportunidades de vivienda a los sectores de menores ingresos, constituye también un productor de desigualdades. La experiencia residencial de los inquilinos nos presenta la peor cara de la densificación, esta es vivida como tugurización y hacinamiento.

¿Hay que volver, entonces, a apostar por la propiedad como la única forma de tenencia capaz de disminuir estos malestares? Creemos que no. El inquilinato no es per se un régimen menos adecuado que la propiedad. Si algo deseamos advertir como conclusión de este texto, es que la solución a dichos malestares debe tener, como base, cambios a nivel del sistema habitacional. Es más, existen razones sólidas para pensar que el inquilinato en asentamientos consolidados está cumpliendo un rol clave en la mitigación del submercado de loteos. Si no existiera esta oferta habitacional, ¿a dónde más se iría la "demanda no efectiva" de viviendas?

Además, el inquilino le cuesta mucho menos al Estado que el ocupante informal de un lote en suelo nuevo, este último demandará gastos en formalización y dotación de servicios básicos que, tarde o temprano, se tendrán que ejecutar para el "cierre de brechas". 
$\mathrm{Si}$, como consideramos, de lo que se trata es de darle carta de ciudadanía al régimen de alquiler popular, las propuestas a nivel del sistema habitacional podrían, también preliminarmente, considerar las siguientes tres líneas de acción:

La primera, garantizar condiciones mínimas de habitabilidad a la demanda. Se debe diseñar estrategias para desincentivar progresivamente el alquiler de cuartos, o cuanto menos regularlo para no generar hacinamiento. Para esto será necesario desarrollar programas de densificación asistida que aprovechen tanto los incentivos de los inquilinos para permanecer en esta forma de tenencia, como los incentivos de los propietarios para aumentar la oferta de departamentos, promoviendo el mejoramiento físico de sus inmuebles y conduciendo la densificación bajo estándares óptimos de habitabilidad.

La segunda, pasar de la formalización de la propiedad del suelo, a la formalización de la tenencia de la vivienda, cualquiera sea su tipo. La política peruana de formalización se convirtió en el principal referente de regularización jurídica de los asentamientos informales en América Latina, desde el enfoque del "derecho de propiedad" de los años noventa. Pero seguir pensado así, es desconocer que la informalidad no es solo un problema de personas que están excluidas de dicho derecho, sino de quienes no cuentan con garantías jurídicas para ejercer y demandar, de forma estable, el derecho a una tenencia segura; cualquiera sea su forma: propiedad individual, propiedad comunal, alquiler.

Las políticas preventivas de la informalidad no solo deben orientarse a las áreas de crecimiento extensivo, sino también hacia los asentamientos populares consolidados. Esto requiere que entendamos que la propiedad ya no puede ser el único objetivo de los programas de formalización, sino también asegurar las garantías jurídicas de la tenencia en alquiler para los inquilinos, protegiéndolos frente a posibles arbitrariedades. Un sistema habitacional sin contratos sólidos, nunca generará bienestar, ni proveerá de un sano equilibrio de poderes entre arrendadores y arrendatarios.

La tercera, por último, aprovechar la oferta existente de los arrendadores domésticos para reducir el campo de acción de los loteadores piratas. Sin embargo aquí, la investigación urbana tiene una deuda, necesitamos conocer mejor quiénes son los arrendadores, cuáles son sus necesidades de vivienda, qué papel cumple el alquiler en su economía familiar. Si no saldamos este déficit de conocimiento, no podremos esbozar cuál sería el punto de equilibrio entre rendimientos económicos adecuados para los propietarios y mejores condiciones de habitabilidad para los inquilinos. 


\section{Bibliografía}

ABRAMO, P. (2012). La ciudad com-fusa: Mercado y producción de la estructura urbana en las grandes metrópolis latinoamericanas. Revista EURE - Revista de Estudios Urbano Regionales, 38 (114), pp.35-69.

BRICEÑO, R. (2010). Libertad para alquilar: El mercado informal de vivienda de Caracas. Territorios, 0 (18-19), pp.103-127. Recuperado de https://revistas.urosario.edu.co/ index.php/territorios/article/view/829/749

CALDERÓn, J. (2011). Titulación de la propiedad y mercado de tierras. Revista EURE - Revista de Estudios Urbano Regionales, 37 (111), pp.47-77.

DE CERTEAU, M. (1984). The practice of the everyday life. Berkeley: University of California Press.

GARCÍA, A., MORENO, F., y GALINDO, J. (2020). Determinantes del crecimiento de viviendas en alquiler en asentamientos informales de Lima (1993-2017). Working paper. Cambridge, MA: Lincoln Institute of Land Policy.

GARCíA, A. (2019). Alquiler de viviendas en asentamientos populares consolidados de Lima. Un acercamiento a la información oficial y a las preferencias locacionales de la demanda. Revista de Ciencia Política y Gobierno, 5(9), pp.7-34. Recuperado de http://revistas. pucp.edu.pe/index.php/cienciapolitica/article/view/21123

GIDDENS, A., y SUTTON, P. (2014). Conceptos esenciales de Sociología. Madrid: Alianza Editorial. LASCOUMES, P., y LE GALÈS, P. (2014). Sociología de la acción pública. México, D.F.: El Colegio de México.

MADDEN, D., y MARCUSE, P. (2018). En defensa de la vivienda. Madrid: Capitán Swing.

MARTUCCELLI, D. (2015). Lima y sus arenas. Poderes sociales y jerarquías culturales. Lima: Cauces Editores.

ÑIQUEN, J. (2018). Entre la necesidad y la acumulación. Una aproximación al rol del suelo y la vivienda en los procesos de reproducción y movilidad social de los sectores populares. El caso de las familias fundadoras de Huaycán, Lima. (Tesis de pregrado). Pontificia Universidad Católica del Perú, Lima.

PARIAS, A. (2010). El mercado de arrendamiento en los barrios informales en Bogotá, un mercado estructural. Territorios, 0 (18-19), pp.75-101. Recuperado de https://revistas. urosario.edu.co/index.php/territorios/article/view/828

PIMENTEL, N. (2017). Subalternos autónomos. Transformaciones periurbanas y tráfico de tierra en el contexto de una sociedad de mercado: Carabayllo, Lima. (Tesis de pregrado). Universidad Nacional Mayor de San Marcos, Lima.

REMY, J., y VoYÉ, L. (2005). La ciudad. ¿Hacia una nueva definición?. Zaragoza: Ediciones Bassarai. 
RIOFRÍO, G., y DRIANT, J. (1987). ¿Qué vivienda han construido?. Nuevos problemas en viejas barriadas. Lima: CIDAP, IFEA, TAREA.

ROLNIK, R. (2017). La guerra de los lugares. La colonización de la tierra y la vivienda en la era de las finanzas. Santiago de Chile: LOM Ediciones.

SENNETT, R. (2003). El respeto. Sobre la dignidad del hombre en un mundo de desigualdad. Barcelona: Anagrama.

SENNETT, R. (2004). El capitalismo y la ciudad. En A. Ramos (Ed.), Lo urbano en 20 autores contemporáneos (pp. 2013 - 2020). Barcelona: Edicions UPC.

SIMMEL, G. (2005). Las metrópolis y la vida mental. Bifurcaciones. Revista de estudios culturales urbanos. (4), pp.1-10. Recuperado de http://www.bifurcaciones.cl/bifurcaciones/ wpcontent/uploads/2005/09/bifurcaciones_004_reserva.pdf

TURNER, F., y FICHTER, R. (Cord.). (1976). Libertad para construir. Ciudad de México: Siglo $\mathrm{XXI}$ editores.

WatAnABE, J. (2013). Poesía Completa. Buenos Aires: Editorial Pre-Textos.

ZOLEZZI, M., TOKESHI, J., y NORIEGA, C. (2005). Densificación habitacional. Una propuesta de crecimiento para la ciudad popular. Lima: Desco. 